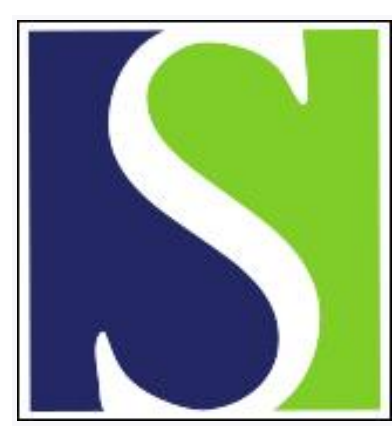

Scand J Work Environ Health 1995;21(5):362-367

https://doi.org/10.5271/sjweh.50

Issue date: Oct 1995

Cancer incidence and mortality of patients with suspected solvent related disorders

by Berlin K, Edling C, Persson B, Ahlborg G, Hillert L, Högstedt B, Lundberg I, Svensson B-G, Thiringer G, Ørbæk P

Key terms: cardiovascular disease; cervix cancer; cohort; lymphohematopoietic malignancies; occupational exposure; organic solvent; suicide; toxic encephalopathy

This article in PubMed: www.ncbi.nlm.nih.gov/pubmed/8571092

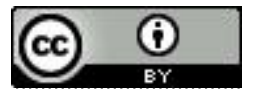




\title{
Cancer incidence and mortality of patients with suspected solvent-related disorders
}

\author{
by Klas Berlin, MD,' Christer Edling, PhD, ${ }^{1}$ Bodil Persson, MD, ${ }^{2}$ Gunnar Ahlborg, PhD, ${ }^{3}$ Lena Hillert, MD, \\ Benkt Högstedt, PhD, Ingvar Lundberg, PhD, ${ }^{6}$ Bengt-Göran Svensson, PhD, ${ }^{7}$ Gunnar Thiringer, PhD, ${ }^{8}$ \\ Palle Ørbæk, $P h D^{9}$
}

\begin{abstract}
Berlin K, Edling C, Persson B, Ahlborg G, Hillert L, Högstedt B, Lundberg I, Svensson B-G, Thiringer G, Ørbæk P. Cancer incidence and mortality of patients with suspected solvent-related disorders. Scand $J$ Work Environ Health $1995 ; 21: 362-7$.
\end{abstract}

\begin{abstract}
Objectives The aim of this study was to study the incidence of cancer and deaths from cancer and other diseases among patients referred to the 11 clinics of occupational medicine in Sweden between 1967 and 1987 for examination because of exposure to organic solvents.

Methods The cohort comprised 5791 persons, 5283 men and 508 women. Information about cancer incidence and causes of death was collected from the Cancer Register of the National Board of Health and Welfare and the National Death Register of Statistics Sweden, respectively. The expected values were calculated from the national death rates and incidence rates of cancer.

Results The overall mortality rate was close to expected, but the mortality rate was decreased for diseases of the circulatory system [standardized mortality ratio (SMR) $0.7,95 \%$ confidence limit (95\% CI) $0.5-0.9$ ] and increased for suicide (SMR 2.0, 95\% CI 1.2-3.2). The total cancer incidence was slightly elevated [standardized incidence ratio (SIR) $1.2,95 \%$ CI $0.99-1.4]$, and some specific cancer sites showed an increased incidence, although the lower confidence limits surpassed one. Malignancies of the lymphohematopoietic system and cancer of the uterine cervix had an increased risk (SIR 1.9, 95\% CI 1.2-3.2, and SIR 3.7, 95\% CI 2.2 - 6.2, respectively). Patients with presumerably high solvent exposure had an SIR of 1.4 for all malignancies (95\% CI 0.9-2.1) and those with presumerably low exposure had an SIR of 1.1 (95\% CI 0.9-1.4).

Conclusions The study showed an increased risk for malignancies of the hematopoietic system and the uterine cervix among patients originally examined with regard to solvent-induced disorders. There was also an increased risk of suicide and a decreased risk of death from diseases of the circulatory system. There was no increased risk for deaths from mental or neurological disorders.
\end{abstract}

Key terms cardiovascular disease, cervix cancer, cohort, lymphomematopoietic malignancies, occupational, organic solvents, suicide, toxic encephalopathy.

Since the beginning of the 19th century, organic solvents have been known to cause acute intoxication when exposure is sufficiently high. Chronic effects have also been observed after long-term exposure. Several cross-sectional studies, based on psychological testing, have shown that long-term exposure to solvents may impair functions of the central nervous system, in particular memory, concentration, perceptual and psychomotor speed, and accuracy. With these different findings as a basis, several workshops have concluded that long-term occupational exposure to organic solvents can cause toxic encephalopathy (1). There has been, however, some criticism of the view that the occupational

1 Department of Occupational and Environmental Medicine, University Hospital, Uppsala, Sweden.

2 Department of Occupational and Environmental Medicine, University Hospital, Linköping, Sweden.

3 Department of Occupational and Environmental Medicine, University Hospital, Örebro, Sweden.

4 Department of Occupational Medicine, Huddinge Hospital, Huddinge, Sweden.

5 Department of Occupational Medicine, Halmstad Hospital, Halmstad, Sweden.

6 Department of Occupational Medicine, Karolinska Hospital, Stockholm Sweden.

7 Department of Occupational and Environmental Medicine, University Hospital, Lund, Sweden.

8 Department of Occupational Medicine, Göteborg, Sweden.

9 Department of Occupational Medicine, General Hospital, Malmö, Sweden.

Reprint requests to: Dr Klas Berlin, Department of Occupational and Environmental Medicine, University Hospital, S-751 85 Uppsala, Sweden. 
inhalation of organic solvents can induce chronic cerebral disease $(2,3)$.

Carcinogenicity is another important aspect of solvent exposure. Benzene is an established human carcinogen, and there is also support for the carcinogenicity of some chlorinated solvents such as chloroform and tetrachloroethylene (4). The International Agency for Research on Cancer has stated that there is sufficient evidence for the carcinogenicity of occupational exposure as a painter (5).

Patients suffering from presumerably solvent-induced diseases such as neuropsychiatric disorders and malignancies or impairment of liver or kidney function constitute a large group of those examined at the clinics of occupational medicine in Sweden. From 1967 to 1987 several thousand people have been examined because of a suspicion of solvent-related health problems. The follow-up of such a cohort could provide valuable information on causes of death and cancer morbidity. One criticism about the existence of toxic encephalopathy due to exposure to solvents is that there might be a tendency to overlook the presence of other diseases among subjects with neuropsychiatric symptoms. Therefore, a follow-up of this kind could serve as a quality control of the clinical investigation.

All 11 hospital-based clinics of occupational medicine in Sweden agreed to take part in a study of the morbidity and mortality of patients suspected of having a solvent-related health problem.

\section{Subjects and methods}

All patients referred to the clinics of occupational medicine in 1967-1987 with a suspected solvent-related disorder were identified in the registers at the various clinics, and data on age, gender, date of first visit to the clinic, and diagnosis [code of the International Classification of Diseases (ICD)] were collected. Two subgroups were also established, one consisting of all women and the other of all patients with a diagnosis of toxic encephalopathy (ICD, eighth revision 347.98; ICD, ninth revision $310 \mathrm{~W}(331 \mathrm{~W})$ ). For a diagnosis of solvent-induced toxic encephalopathy, the following requirements needed to be met (6): prolonged or heavy exposure to solvents, or both; relevant symptoms such as increased fatigue, memory impairment, difficulty to concentrate, and personality changes such as passivity; pathological findings on some objective measure (in general psychological function tests, for example); a time relationship between exposure and the development of signs and symptoms; and finally no other obvious cause for the disease.

There was no detailed information available about exposure in the whole cohort. However, data about occu- pation, exposure time, and type of solvent was obtained from a randomized sample of the noncases in the cohort. The most common jobs were house painter, mechanic, work in the chemical-processing industry, and printer. Most of the workers were exposed to a mixture of solvents, particularly white spirit, xylene, and toluene.

When the diagnosis of toxic encephalopathy is considered, prolonged exposure to organic solvent(s) is normally 10 or more years at exposure levels around $50-$ $100 \%$ of the hygienic effect, and heavy exposure is exposure to levels exceeding twice the hygienic effect.

Information about cancer incidence and causes of death was collected from the Cancer Register of the National Board of Health and Welfare, and the National Death Register of Statistics, Sweden, respectively.

During the study period, 5791 individuals were referred to the clinics because of suspected solvent-related disorders. Of the 5791, there were 5283 men and 508 women. The mean age was 44.7 and 43.3 , respectively. The subjects were followed from the time of first visit to the clinic until the date of cancer diagnosis, death, or the end of the study period, 31 December 1987. All of the patients were traced, but 138 with a cancer diagnosis at the time they were referred to the clinic were excluded, leaving 5653 patients with a total of 26754 person-years for the statistical analyses.

The epidemiologic analyses were performed using the computer program EPILUND at the Department of Occupational and Environmental Medicine, University Hospital in Lund, Sweden. This program calculates a matrix of person-years of observation and expected values based on the cause, gender, and five-year agespecific national death rates and incidence rates of cancer. Finally, it computes standardized mortality ratios (SMR) and standardized incidence ratios (SIR), and also 95\% confidence intervals (95\% CI) based on the Poisson distribution, or the normal distribution if the expected value was greater than 15 .

Since information from other epidemiologic studies had indicated a possible connection between occupational exposure to organic solvents and cancer of the uterine cervix, special attention was given to this cancer site $(7-10)$. Of the 508 women in the cohort, 32 had a malignant transformation of the cervix. In most cases this had occurred before the patient's first visit to the occupational health clinic. Therefore they were not included when incidence rates were calculated for the entire cohort by the EPILUND program. For all cases of cancer of the uterine cervix data on exposure were collected, and for 18 cases there was no occupational exposure to organic solvent(s) prior to the diagnosis. The remaining 490 women of this subcohort had an average age of 43.3 (SD 11.9, range 16-67) years and contributed with a total of 2519 person-years. The study period for this subcohort was 1969-1987 since the first female 
entered the cohort in 1969. Information on cancer incidence for 1969-1987 was collected from the Swedish Cancer Register at the National Board of Health and Welfare. The expected value for cancer of the cervix (ICD9 180) was calculated for specific national incidence rates for five-year groups. To calculate the relative risk ( $R R$ ), the observed number of cases was divided by the expected number and the confidence intervals (CI) were calculated according to a normal distribution approximation of the Poisson distribution.

\section{Results}

\section{Cancer mortality and morbidity}

The number of deaths from malignant diseases was slightly increased (table 1). Increased risk estimates were noted for numerous specific sites, such as Hodgkin's lymphoma [standardized mortality ratio (SMR) 6.3] and leukemia (SMR 2.3) and cancer of the mouth and throat (SMR 1.7), the central nervous system (SMR 1.7), the urinary bladder (SMR 1.6), the prostate (SMR 1.5), and the respiratory tract (SMR 1.4).

The cohort included 118 incident cases of cancer (ICD9 140-209) with an increased SIR of 1.2 (95\% CI $0.99-1.4$ ) for all malignancies (table 2). Some specific sites showed an increased risk, that is, the nose and nasal sinuses (SIR 7.2), female genital organs (SIR 3.0), larynx
(SIR 2.2), leukemia (SIR 2.1), bone or connective tissue (SIR 2,0), myelomatosis (SIR 2,0), malignant lymphoma (SIR 1.8), skin (excluding melanoma) (SIR 1.5), prostate (SIR 1.3), kidney (SIR 1.2), cancer of the gastrointestinal tract (SIR 1.1), and tumors of unspecified sites (SIR 1.4). For all of these cancer sites the lower confidence interval surpassed one, and for most cancers the risk estimates were based on few observed cases. When all malignancies of the hematopoietic system (ICD9 200207) were combined, an increased risk was revealed (SIR $1.9,95 \%$ CI 1.6-3.6).

An increased risk was also found for carcinoma of the uterine cervix (SIR 3.7, 95\% CI 2.2-6.2).

There were some differences in cancer mortality and cancer incidence between the groups with and without a diagnosis of toxic encephalopathy, mainly regarding skin tumors (not melanoma) with an SIR of 4.7 (95\% CI $0.97-13.7)$ and $0.5(95 \%$ CI $0.01-2.6)$, respectively. For other cancers the incidence and mortality were about the same.

\section{Mortality from causes other than cancer}

Increased risks were found for violent death and poisoning (SMR 1.3, 95\% 0.9-1.9) and suicide (SMR 2.0 95\% CI 1.2-3.2) (table 1). Those with a diagnosis of toxic encephalopathy had an SMR of 1.5 (95\% CI 0.2-5.4), and for those without this diagnosis the SMR was 2.1 (95\% CI 1.2-4.4). In both groups there was a decrease

Table 1. Mortality rates in a cohort of solvent-exposed patients referred to clinics of occupational medicine in Sweden. Only sites with at least two observed cases are given. ( $\mathrm{SIR}=$ standardized incidence ratio, $95 \% \mathrm{Cl}=95 \%$ confidence interval)

\begin{tabular}{|c|c|c|c|c|}
\hline Site $^{a}$ & $\begin{array}{l}\text { Observed } \\
\text { number }\end{array}$ & $\begin{array}{c}\text { Expected } \\
\text { number }\end{array}$ & SIR & $95 \% \mathrm{Cl}$ \\
\hline Mouth and throat $(140-149)$ & 2 & 1.17 & 1.7 & $0.2-6.2$ \\
\hline Gastrointestinal tract $(150-154)$ & 6 & 10.46 & 0.6 & $0.2-1.3$ \\
\hline Stomach (151) & 2 & 3.73 & 0.5 & $0.1-1.9$ \\
\hline Colon (153) & 2 & 3.25 & 0.6 & $0.1-2.2$ \\
\hline Rectum (154) & 2 & 2.01 & 0.99 & $0.1-3.6$ \\
\hline Respiratory system $(160-164)$ & 16 & 11.24 & 1.4 & $0.8-2.4$ \\
\hline Trachea, lung, pleura (162-164) & 15 & 10.86 & 1.4 & $0.8-2.3$ \\
\hline Prostate (185) & 6 & 3.98 & 1.5 & $0.6-3.3$ \\
\hline Kidney, urinary tract (189) & 2 & 2.53 & 0.8 & $0.1-2.9$ \\
\hline Urinary bladder (188) & 2 & 1.25 & 1.6 & $0.2-5.8$ \\
\hline Central nervous system $(191-192)$ & 4 & 2.34 & 1.7 & $0.5-4.4$ \\
\hline Others, unspecified (199) & 4 & 1.96 & 2.0 & $0.6-5.2$ \\
\hline Hodgkin's lymphoma (201) & 2 & 0.32 & 6.3 & $0.8-22.7$ \\
\hline Leukemia (204-207) & 4 & 1.76 & 2.3 & $0.6-5.8$ \\
\hline All malignant tumors $(140-208)$ & 58 & 49.50 & 1.2 & $0.9-1.5$ \\
\hline Endocrine, metabolic diseases $(240-279)$ & 2 & 2.96 & 0.7 & $0.1-2.4$ \\
\hline Mental disorders $(290-315)$ & 4 & 4.37 & 0.9 & $0.3-2.3$ \\
\hline Respiratory system (460-519) & 6 & 9.02 & 0.7 & $0.2-1.5$ \\
\hline Digestive system $(520-579)$ & 11 & 7.47 & 1.5 & $0.7-2.6$ \\
\hline Suicide (E950-E959) & 18 & 9.06 & 2.0 & $1.2-3.2$ \\
\hline Violent death, poisoning (E800_E999) & 31 & 23.53 & 1.3 & $0.9-1.9$ \\
\hline Liver cirrhosis, alcohol induced (571) & 2 & 2.05 & 1.0 & $0.1-3.5$ \\
\hline Circulatory system $(390-459)$ & 63 & 90.88 & 0.7 & $0.5-0.9$ \\
\hline Death, all causes $(000-999)$ & 182 & 195.41 & 0.9 & $0.8-1.1$ \\
\hline
\end{tabular}

a Code of the International Classification of Diseases, ninth revision, in parentheses. 
Table 2. Cancer incidence in a cohort of solvent-exposed patients referred to clinics of occupational medicine in Sweden. Only sites with at least two observed cases are given. ( $\mathrm{SIR}=$ standardized incidence ratio, $95 \% \mathrm{Cl}=95 \%$ confidence interval)

\begin{tabular}{|c|c|c|c|c|}
\hline Site $^{\mathrm{a}}$ & $\begin{array}{c}\text { Observed } \\
\text { number }\end{array}$ & $\begin{array}{l}\text { Expected } \\
\text { number }\end{array}$ & SIR & $95 \% \mathrm{Cl}$ \\
\hline Mouth and throat (140-149) & 2 & 3.86 & 0.6 & $0.1-2.2$ \\
\hline Gastrointestinal tract $(150-154)$ & 20 & 18.04 & 1.1 & $0.7-1.7$ \\
\hline Stomach $(\uparrow 51)$ & 5 & 4.83 & 1.0 & $0.3-2.4$ \\
\hline Colon (153) & 7 & 6.70 & 1.0 & $0.4-2.2$ \\
\hline Rectum (154) & 6 & 4.64 & 1.3 & $0.5-2.8$ \\
\hline Liver, bile ducts (155) & 2 & 2.36 & 0.9 & $0.1-3.1$ \\
\hline Respiratory system (160-164) & 20 & 13.62 & 1.5 & $0.9-2.4$ \\
\hline Nose, sinuses $(160)$ & 2 & 0.28 & 7.2 & $0.9-26.0$ \\
\hline Larynx (161) & 3 & 1.35 & 2.2 & $0.5-6.5$ \\
\hline Trachea, lung, pleura (162-164) & 15 & 11.69 & 1.3 & $0.7-2.1$ \\
\hline Breast (174) & 3 & 2.76 & 1.1 & $0.2-3.2$ \\
\hline Female genital organs $(179-184)$ & 5 & 1.68 & 3.0 & $0.97-7.0$ \\
\hline Uterine cervix ${ }^{b}(180)$ & 14 & 3.8 & 3.7 & $2.2-6.2$ \\
\hline Prostate (185) & 17 & 13.18 & 1.3 & $0.8-2.1$ \\
\hline Other genital organs (187) & 2 & 0.40 & 5.0 & $0.6-18.0$ \\
\hline Kidney (189) & 6 & 4.90 & 1.2 & $0.5-2.7$ \\
\hline Urinary bladder (188) & 5 & 6.88 & 0.7 & $0.2-1.7$ \\
\hline Melanoma (†72) & 3 & 4.42 & 0.7 & $0.1-2.0$ \\
\hline Skin, not melanoma (173) & 4 & 2.60 & 1.5 & $0.4-4.0$ \\
\hline Central nervous system (191-192) & 4 & 4.48 & 0.9 & $0.2-2.3$ \\
\hline Bone, connective tissue $(170-171)$ & 2 & 1.02 & 2.0 & $0.2-7.1$ \\
\hline Others, unspecified (199) & 4 & 2.80 & 1.4 & $0.4-3.7$ \\
\hline Lymphoma $(200-202)$ & 8 & 4.42 & 1.8 & $0.8-4.6$ \\
\hline Non-Hodgkin's lymphoma $(200,202)$ & 7 & 3.6 & 1.9 & $0.8-4.0$ \\
\hline Myelomatosis (203) & 3 & 1.53 & 2.0 & $0.4-5.7$ \\
\hline Leukemia $(204-207)$ & 6 & 2.83 & 2.1 & $0.8-4.6$ \\
\hline Lymphohematopoietic system (200-207) & 17 & 8.78 & 1.9 & $1.2-3.2$ \\
\hline All malignant tumors (140-208) & 118 & 99.39 & 1.2 & $0.99-1.4$ \\
\hline
\end{tabular}

a Code of the International Classification of Diseases, ninth revision, in parentheses.

b Result from computing the female subcohort; see the text.

in the risk from death due to diseases of the circulatory system, and the combined SMR was 0.7 (95\% CI $0.5-$ $0.9)$. The number of observed deaths from hepatic cirrhosis was not increased (SMR 1.0, 95\% CI 0.1-3.6). There were two cases, both belonging to the group without a diagnosis of toxic encephalopathy.

\section{Discussion}

The study showed an increased risk for malignancies of the hematopoietic system among patients referred to clinics of occupational medicine with a presumptive diagnosis of a solvent-related disorder. These patients also had an increased risk of suicide and a decreased risk of death from diseases of the circulatory system. There was no overall increase in the morbidity or mortality from malignancies.

The study is a follow-up of a highly selected group of patients, and one drawback was that the recorded exposure information was too scant to allow for any definite conclusions regarding duration and type of solvent. One of the reasons for performing this study was the concern about other serious diseases hidden in this group of patients complaining of neuropsychiatric symptoms, par- ticularly among those with a diagnosis of toxic encephalopathy. It could be possible that brain tumors or other neurological and mental disorders might be overlooked due to a tendency to explain the patient's symptoms in terms of solvent exposure. The increased risk of suicide indicates that there might have been numerous undiagnosed depressive states in the cohort. Otherwise there was no indication of the presence of systematic errors in clinical diagnosis in the study, since no increased risks were found for cancer of the central nervous system, or deaths from mental or neurological diseases. That the entity solvent-induced toxic encephalophaty does not hide other neurological or psychiatric diseases is supported by another of our studies. In a five-year follow-up of 46 men with solvent-induced toxic encephalopathy, there were no cases of dementia or neurological disease (11).

The use of the general population as a reference in cohort studies is often questioned, since it includes groups with different morbidity patterns as compared with workers with long-time employment. Thus the observed number of deaths in an occupational cohort is often less than expected, resulting in the healthy worker effect. The healthy worker effect differs for different types of diseases. Hernberg stresses that the healthy worker effect is strong for respiratory and cardiovascular 
diseases and weak for cancer (12). In this cohort there was a decrease in cardiovascular deaths, an increase in respiratory deaths, and an increase in cancer mortality. Thus the pattern was not as could be expected if there had been a strong healthy worker effect operating in the cohort. Therefore we do not believe that the healthy worker effect was an important source of error in this cohort study.

Seventeen of the patients developed malignant disease of the lymphohematopoietic system: eight cases of lymphoma, three of myeloma, and six of leukemia. When these different sites were combined, the SIR was 1.9 (95\% CI 1.2-3.2). This value congrues with results from other studies indicating that occupational exposure to solvents may increase the risk for malignant transformation in the lymphohematopoietic system (10, 13 16). The mean exposure time to organic solvents for this group of patients was 20 (SD 7.7, range 6-34) years. Sixteen of the cases belonged to the group that did not have a diagnosis of toxic encephalopathy. From these findings, and the fact that the average time from the first visit to an occupational health clinic until the cancer diagnosis was only 4.6 years, one might speculate whether vague symptoms of the neurasthenic type are early indicators of malignant disease. There is some support for this idea in other studies (17).

The increase in carcinoma of the cervix deserves a comment. Four earlier studies found an increased risk for this type of tumor among women occupationally exposed to solvents $(7-10)$. There are also data from animal experiments which show both accumulation and biotransformation of halogenated solvents in the cervico vaginal epithelium of rodents (18-21). Apparently these cells have the capacity to metabolize and bioactivate these types of compounds. Although one could dispute whether the presence of metabolites in the cells of the epithelial lining of the cervix is of toxicologic significance, it shows that some solvents may reach the cells from which the carcinoma arises. The major risk factors for cancer of the cervix have been sexual behavior, socioeconomic status, smoking, and viral infections (eg, by human papilloma viruses) $(22-24)$. Although we do not have information on all of these risk factors, our data support the possibility of an increased risk for carcinoma of the cervix among women occupationally exposed to organic solvents, and this issue should be considered in future epidemiologic studies of occupational cancer risks among women.

A decreased risk of death from diseases of the circulatory system was noted. This could have been a chance phenomenon, a healthy worker effect, a selection bias, or it may reflect some protective factor in the work environment. As discussed earlier, we do not believe that a healthy worker effect or a strong selection bias was operating in this cohort. Low alcohol consumption has been suggested as a protective factor for cardiovascular disease in some studies $(25-27)$, but, in this study, data on deaths from alcohol-induced liver cirrhosis and violent deaths do not support the possibility that the alcohol consumption in the cohort differed significantly from that of the general population. The mechanisms discussed for alcohol and cardiovascular disease involve effects on lipid metabolism, but, as far as we know, there have been no studies of the effects of long-term occupational exposure to solvents on lipid metabolism (28-31). The findings also imply that the symptoms of the central nervous system that led to the investigations of toxic encephalopathy were not caused by arteriosclerotic disease.

There was an increased risk of death from suicide in the group when the group was compared with the general population. Such an observation has generally not been reported in other studies of solvent workers. However, the suicide rate among Swedish painters was almost twice as high as that of plumbers or pipe fitters (32). In our study there were also some differences between the group with a diagnosis of toxic encephalopathy and the group without the diagnosis (SMR 1.5 and 2.1, respectively). This finding could be due to depression, and a higher prevalence of depression has been reported among solvent-exposed floorlayers when they were compared with unexposed carpenters (33).

As mental depression is a differential diagnosis for toxic encephalopathy, this finding is important. A depressive state should always be considered when a patient suspected of having toxic encephalopathy is examined, as the symptoms may be similar in both conditions. It is also worth considering whether the depression is part of the syndrome of toxic encephalopathy or separate from it. A psychiatric opinion should be sought for this group of patients more often than is currently the case.

\section{Acknowledgments}

We acknowledge the contribution of Dr B Hellman, Dr O Marqvardsen, Professor L Dencker, and the Swedish Cancer Society.

This study was financially supported by the Swedish Work Environment Fund, grant no 90-0241.

\section{References}

1. Baker EL. A review of recent research on health effects of human occupational exposure to organic solvents. J Occup Med 1994;36:1079-92.

2. Errebo-Enudsen EO, Olsen F. Organic solvents and presenile dementia (the painters syndrome): a critical review of the Danish literature. Sci Total Environ 1986;48:45-67. 
3. Grasso P, Sharrat M, Davies DM, Irvine. Neurophysiological and psychological disorders and occupational exposure to organic solvents. Fd Chem Toxicol 1984;22:819-52.

4. International Agency for Research on Cancer (IARC). Overall evaluation of carcinogenicity: an updating of IARC Monographs volumes 1 to 42. Lyon: France, 1987. IARC monographs on the evaluation of carcinogenic risks to humans, suppl 7.

5. International Agency for Research on Cancer (IARC). Some organic solvents, resin monomers and related compounds, pigments and occupational exposure in paint manufacture and painting. Lyon: IARC, 1989:424. IARC monographs on the evaluation of carcinogenic risks to humans, vol 47.

6. Joint World Health Organization/Nordic Council of Ministers Working Group. Chronic effects of organic solvents on the central nervous system and diagnostic criteria. Copenhagen: World Health Organization, 1985.

7. Blair A, DeCouffle P, Grauman DJ. Causes of death among laundry and dry cleaning workers. Am J Public Health 1979;69:508-11.

8. Katz RM, Jowett D. Female laundry and dry cleaning workers in Wisconsin: a mortality analysis. Am J Public Health 1981; $71: 305-7$.

9. Blair A, Stewart PA, Tolbert PE, Grauman D, Moran FX, Vaught $J$, et al. Cancer and other causes of death among a cohort of dry cleaners. Br J Ind Med 1990;47:162-8.

10. Wong O, Trent LS, Whorton MD. An updated cohort mortality study of workers exposed to styrene in the reinforced plastics and composites industry. Occup Environ Med 1994;51: 386-96.

11. Edling C, Ekberg K, Ahlborg G, Alexandersson R, Barregård L, Ekenvall L, et al. Long term follow up of workers exposed to solvents. Br J Ind Med 1990;47:75-82.

12. Hernberg S. Healthy worker effect. In: Hernberg S. Introduction to occupational epidemiology. Chelsea: Lewis Publishers, 1992:129-33.

13. Lindquist R, Nilsson B, Eklund G, Gahrton G. Increased risk of developing acute leukemia after employment as a painter. Cancer 1987;60:1378-84.

14. Olsson H, Brandt L. Risk of non-Hodgkin's lymphoma among men occupationally exposed to organic solvents. Scand J Work Environ Health 1988;14:246-51.

15. Persson B, Dahlander A-M, Fredriksson M, Noorlind-Brage H, Ohlsson C-G, Axelson O. Malignant lymphomas and occupational exposures. Br J Ind Med 1989;46:516-20.

16. Persson B, Fredriksson M, Olsen K, Boeryd B, Axelson O. Some occupational exposures as risk factors for malignant lymphomas. Cancer 1993;72:1773-8.

17. Frentzel-Reyme R. The role of the central nervous involvement in occupational cancer risk of persons exposed to organic solvents. In: Sakurai H, Okazaki I, Omae K, editors. Occupational epidemiology. Amsterdam: Elsevier Science Publishers BV, 1990:83-8.

18. Brittebo EB, Brandt I. Metabolic activation of carbon tetrachloride by the cervico-vaginal epithelium in rodents. Phar- macol Toxicol 1989;65:336-42.

19. Bergman K. Whole-body autoradiography and allied tracer techniques in distribution and elimination studies of some organic solvents. Scand J Work Environ Health 1979;5 suppl $1: 1-263$.

20. Kowalski B, Brittebo EB, Brandt I. Epithelial binding of 1,2dibromomethane in the respiratory and upper alimentary tracts of rats and mice. Cancer Res 1985;45:2616-25.

21. Brittebo EB, Kowalski B, Brandt I. Binding of the aliphatic halides 1,2-dibromomethane and chloroform in the rodent vaginal epithelium. Pharmacol Toxicol 1987;60:294-98.

22. Herity B. Role of alcohol, tobacco and socio-economic factors in the development of cancer. In: Stoll BA, editor. Risk factors and multiple cancer. Chichester: Wiley, 1984:83-102.

23. Vessey MP. Epidemiology of cervical cancer: role of hormonal factors, cigarette smoking and occupation. Banbury Rep 1986;21:29-43.

24. Kiviat NB, Koutsky LA. Specific human papillomavirus types as the causal agents of most cervical intraepithelial neoplasia: implications for current views and treatment [editorial]. JNCI 1993;85:934-5.

25. Klatsky AL, Armstrong MA, Friedman GD. Risk of cardiovascular mortality in alcohol drinkers, ex-drinkers and nondrinkers. Am J Cardiol 1990;66:1237-42.

26. Klatsky AL, Armstrong MA, Friedman GD. Alcohol and mortality. Ann Intern Med 1992;117:646-54.

27. Peele S. The conflict between public health goals and the temperance mentality. Am J Public Health 1993;83:805-10.

28. Langer RD, Criqui MH, Reed DM. Lipoproteins and blood pressure as biological pathways for effect of moderate alcohol consumption on coronary heart disease. Circulation 1992;85: $910-5$.

29. Gaziano JM, Buring JE, Breslow JL, Goldhaber SZ, Rosner B, VanDenburgh $\mathrm{M}$, et al. Moderate alcohol intake, increased levels of high-density lipoprotein and its subfractions, and decreased risk of myocardial infarction. N Engl J Med. 1993; 329:1829-34.

30. Sillanaukee P, Koivula T, Jokela H, Myllyharju H, Seppä K. Relationship of alcohol consumption to changes in HDL-subfractions. Eur J Clin Invest 1993;23:486-91.

31. Amarasuriya RN, Gupta AK, Civen M, Horng YC, Maeda T, Kashyap ML. Ethanol stimulates apolipoprotein A-I secretion by human hepatocytes: implications for a mechanism for atherosclerosis protection. Metabolism 1992;41:827-32.

32. Engholm G, Englund A. Cancer incidence and mortality among Swedish painters. In: Englund A, Ringen K, Mehlman MA, editors. Advances in modern environmental toxicology; vol II (Occupational health hazards of solvents). Princeton, NJ: Princeton Scientific Publishing Co, 1982:173-85.

33. Ekberg K, Barregård L, Hagberg S, Sällsten G. Chronic and acute effects of solvents on central nervous system functions in floorlayers. Br J Ind Med 1986;43:101-6.

Received for publication: 26 August 1994 